\title{
A Rare Presentation of Nodular Growth over Right Anterior Chest Wall in an Elderly Male Mimicking Carcinoma Breast
}

\author{
R.K. Maurya, M.S., Pawan Singh M.S., Vivek Garg M.B. \\ Department of Surgery, G.S.V.M. Medical College, Kanpur (UP), India
}

\section{A B S T R A C T}

Malignant malenoma in chest wall are rare, although reported. We hereby report a 60 year male who presented with nodular growth over anterior chest wall mimicking breast carcinoma. JMS 2010;13(2):70-71

Key words: Breast carcinoma, malignant malenoma

The differential diagnosis of chest wall tumors is diverse, including both benign and malignant lesions, and local extension of adjacent disease. Chest wall tumors can arise from the soft tissue and osseous structures of the thorax, which include the ribs, cartilage, nerves, muscles, fat, and lymph nodes. We present rare presentation of a nodular growth over right anterior chest wall in an elderly male mimicking carcinoma breast.

\section{Case Report}

A sixty five years old man presented with a nodular growth of size 3 into $3 \mathrm{~cm}$. over a black nevus measuring in size about 8 into $6 \mathrm{~cm}$ over the right anterior chest wall. The growth was

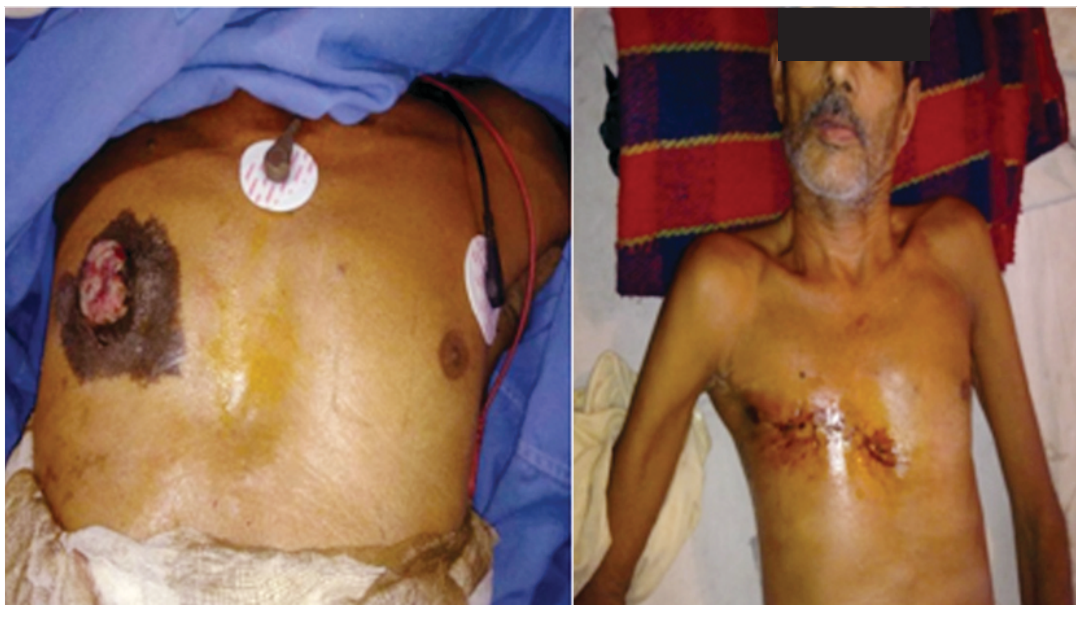

FIGURE 1: Showing nodular growth over right anterior chest wall (Left panel) and after resection (Right panel) ulcerated and associated with itching and mild pain. Patient had noticed this growth four months back which was initially small (near about size of a pea), and it gradually enlarged and formed a nodular growth measuring about 3 into $3 \mathrm{~cm}$ (As mentioned earlier).

Patient was a first issue of a non-consanguineous

Address for Correspondence and reprint requests to:

Dr. R. K. Maurya

Assistant Professor,

Department of Surgery, G. S. V. M. Medical College, Kanpur, U.P, India

drrajeshpuru2007@rediffmail.com marriage, with an unremarkable natal and post natal history. $\mathrm{He}$ was a non smoker, non alcoholic, and a farmer by occupation belonging to the low socio-economic strata, No other family member suffered from a similar disease. On examination a black nevus was present over right anterior chest wall, just medial to nipple of size about 8 into $6 \mathrm{~cm}$. with irregular margins. This nevus showed a projecting nodular growth of size about 3 into $3 \mathrm{~cm}$. with ulceration. Patient also had right axillary lymphadenopathy, two in number which was mobile, about 1 into $1.5 \mathrm{~cm}$. in greatest diameter, firm and non-tender. No other nevus was found elsewhere and rest of examination was unremarkable. His routine $\mathrm{CBC}$ revealed iron deficiency 


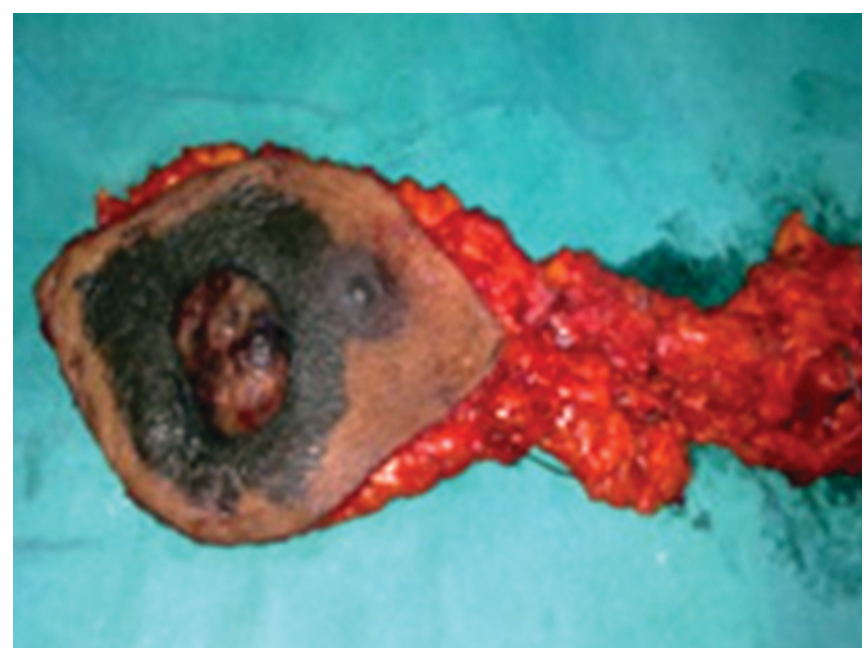

FIGURE 2: image of gross excised specimen with axillary lymph nodes most important predisposing factors are inherited genes and sun exposure. ${ }^{2}$ The risk factors for developing malignant melanoma are xeroderma pigmentosum, dysplastic naevi, high total number of naevi, previous melanoma, family history of malignant melanoma with dysplastic naevi, red hair, tendency to freckle, immunocompromised conditions like HIV infection, Hodgkins disease, steroid therapy, history of sunburn specially in childhood. ${ }^{3}$ There are four common macroscopic variants of MM with some rare forms. Superficial spreading melanoma is the commonest $(70 \%)$ one, Nodular melanoma (15\%), Lentigo maligna melanoma. Acral lentiginous melanoma, amelanotic melanoma, desmoplastic melanoma. Biopsy and pathological examination provide the first step towards staging melanoma. The Breslow thickness of a melanoma is the most important prognostic indicator in the absence of lymph node metastases. The American Joint Committee on Cancer (AJCC) gives staging for MM. Treat-
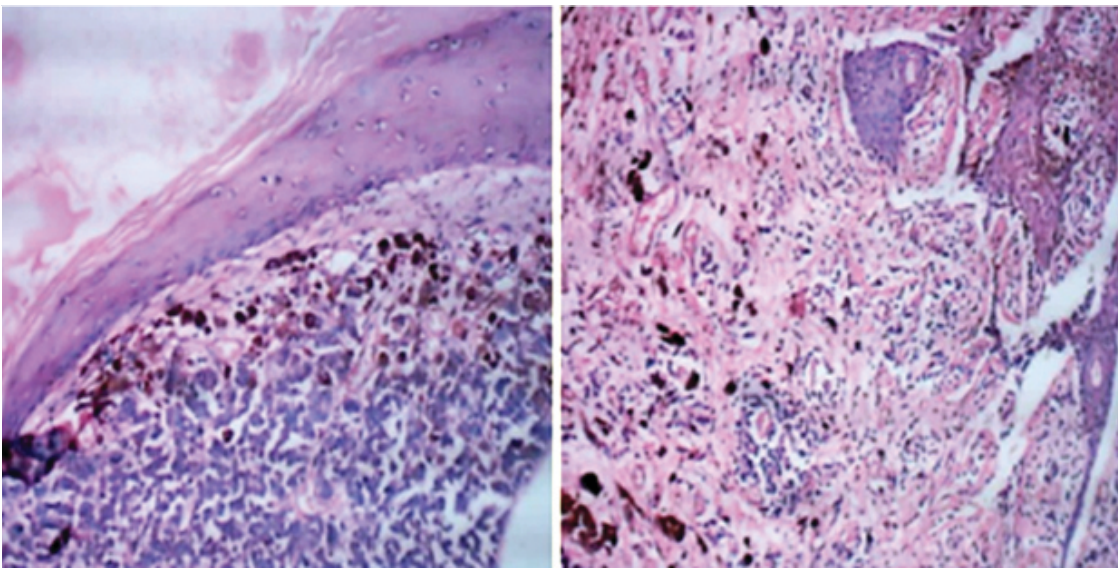

FIGURE 3: Histopathology of growth

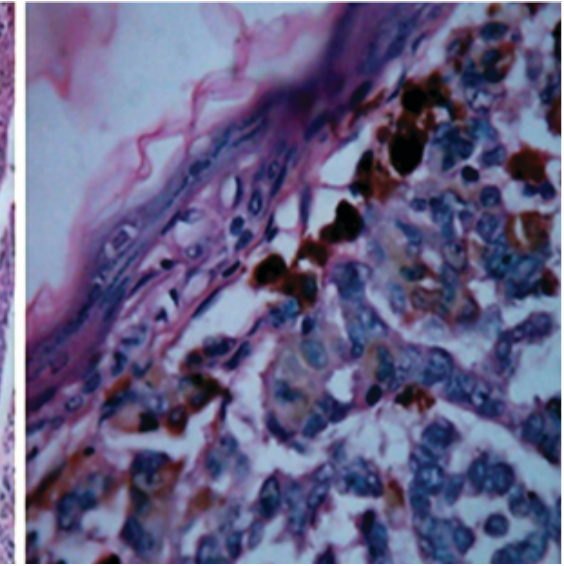

anemia. His chest X-ray, 12 lead ECG and sonography of the whole abdomen were normal. His retrovirus status was nonreactive. Punch biopsy of the lesion showed malignant epithelial neoplasm disposed in clusters and nest, reaching upto reticular dermis, individual tumor cell was round to oval in shape, had high nucleo-cytoplasmic ratio, hyperchromatic nuclei and prominent nucleoli, fair no. of mitoses and moderate amount of melanin pigment were seen. A wide local excision of the growth with block axillary lymph node dissection of right side was performed under general anaesthesia and the gross excised specimen (Figure 2) was sent for histopathology and diagnosis of Malignant Melanoma (Clark Level, 3/4) was confirmed.

\section{Discussion}

Malignant melanoma is a cancer of the melanocytes. It usually arises in the skin but can occur anywhere that melanocytes exist, such as anogenital mucosal surface, retina, leptomeninges and oesophagus. Worldwide it accounts for 3\% of all malignancy. It is the commonest cancer in young adults and is the most likely cause of cancer related death. The two ment of choice is wide local excision with $2 \mathrm{~cm}$ margin with block dissection of regional lymph node for biopsy positive nodal disease. ${ }^{4}$

\section{References}

1. Russel R.C.G, Williams N.S, Bulstrode C.J.K (editors). Bailey and love's short practice of surgery. 25th ed. London: Chapman and Hall, 2008.

2. Robbins and Cotran pathologic basis of disease. 8th ed. Philadelphia: Elsevier Saunders; 2010.

3. Rhodes AR, Weinstock MA, Fitzpatrick TB, Mihm MC Jr, Sober AJ. Risk factor for cutaneous melanoma. A practical method of recognizing predisposed individuals. JAMA 1987;258(21):3146-54.

4. Sabiston textbook of surgery. 15th ed. WB Saunders; 1997.

5. DeVita VT, Hellman S, Rosenberg SA, editors. Cancer: principles and practice of oncology, 5th ed. Philadelphia: Lippincott-Raven; 1997 